\title{
A pedagogia de Valdeci: lutas e papel sociopolítico de uma professora quilombola no Sertão de Pernambuco ${ }^{1}$
}

\author{
$\mathrm{M}^{\mathrm{a}}$ Rosiclaudia dos Santos Ferreira ${ }^{2}$ \\ rosiclaudia1@gmail.com
}

\begin{abstract}
Whodson Silva ${ }^{3}$
Doutorando em Antropologia na Universidade Federal de Minas Gerais - UFMG whodsoon@gmail.com
\end{abstract}

\begin{abstract}
Resumo: O trabalho destaca as lutas e a trajetória sociopolitica de Valdeci Ana dos Santos Nascimento enquanto mulher, professora e liderança do Quilombo Poço dos Cavalos em Itacuruba, Sertão de Pernambuco. A compreensão do lugar desta na luta por direitos específicos e diferenciados para sua comunidade provoca, ao mesmo tempo, a reflexão de sua história de vida e importância pedagógica no processo de organização sociopolitica do grupo. Minha condição de mulher, professora e quilombola, faz com que eu considere minhas próprias percepções e vivências, o que conforma uma importante dimensão metodológica na construção deste trabalho. O quilombo Poço dos Cavalos busca a autonomia local e luta por seus próprios espaços de interação no campo: o território tradicionalmente ocupado e uma escola nesse território. E nesse contexto que as mulheres, como Valdeci, têm sido as diretamente envolvidas na organização do movimento quilombola no Sertão de Pernambuco, lutando por direitos e justiça social.
\end{abstract}

Palavras-chaves: Quilombos em Pernambuco; Mulheres quilombolas; Itacuruba-PE.

Abstract: The present work highlights Valdeci Ana dos Santos Nascimento's struggles and sociopolitical path as a woman, teacher and leader at Quilombo Poço dos Cavalos in Itacuruba, at the Brazilian state of Pernambuco's hinterland. Understanding her place in this fight for specific and distinguished rights causes, at the same time, a reflection on her life story and on her pedagogical importance in the quilombo's sociopolitical organization process. My condition as a woman, teacher and quilombola, makes me look at my own perception and experiences, and that constitutes an important methodological dimension on the construction of this work. Quilombo Poço dos Cavalos seeks for local autonomy and fights for its own interaction spaces at the district: traditionally occupied territory and a school within it. It's in this context that women, like Valdeci, have been directly involved in the quilombola movement in Pernambuco's hinterland, fighting for rights and social justice.

Keywords: Quilombos in Pernambuco; Quilombola women; Itacuruba-PE.

1 O presente artigo é resultante do trabalho de conclusão de curso da Especialização em Educação Intercultural: Indígenas e Quilombolas ofertado no Instituto Federal de Educação, Ciência e Tecnologia do Sertão Pernambucano - Campus Floresta em 2019.

2 Quilombola da Comunidade Poço dos Cavalos em Itacuruba, Sertão de Pernambuco. Licenciada em Educação do Campo pelo Centro de Ensino Superior do Vale do São Francisco (CESVASF), e especialista em Educação Intercultural: indígenas e quilombolas pelo Instituto Federal do Sertão Pernambucano, campus Floresta.

3 Professor do curso de especialização em Educação Intercultural: indígenas e quilombolas no Instituto Federal do Sertão Pernambucano, campus Floresta. Integrante do núcleo Pernambuco do Projeto Nova Cartografia Social da Amazônia (PNCSA).

EntreRios - Revista do PPGANT -UFPI -Teresina • Vol. 3, n. 1 (2020) 


\section{Introdução à pedagogia de Valdeci}

O respeito às diferenças é, ainda, um dos maiores desafios no convívio em sociedade. É recorrente o número de situações em que se manifestam tensões e posturas de intolerância à diversidade, sendo esta uma das condições inerentes à vida humana. Nesse campo, os "quilombos" ou "remanescente de quilombos" "são grupos sociais cujas identidades coletivas distingue-os da sociedade envolvente, a partir de um processo de auto identificação social e étnica. Tal distinção faz com que esses sejam muitas vezes reproduzidos no imaginário social por meio da invisibilidade e do estereótipo.

Ainda que aos quilombos seja reconhecida juridicamente a sua identidade e o direito ao território tradicionalmente ocupado, conforme a Constituição Federal de 1988 e o Decreto $n^{\circ}$ 4.887 de 20 de novembro de 2003, encontram-se dificuldades na efetivação e no respeito a esses direitos. Os quilombolas podem ser entendidos como descendentes de africanos escravizados que reelaboram, ao passo da história, tradições culturais, religiosas e de subsistência, o que exprime uma histórica e atualizada resistência as diferentes formas de domínio. Pressupõe, portanto, uma complexa relação entre o passado - de pessoas com história; o presente - de pessoas que existem hoje; e o futuro - de pessoas que projetam coletivamente suas existências.

Para Almeida (2002), os quilombos não podem ser vistos a partir de um modelo passadista que entende unicamente os e as quilombolas como "remanescentes", ou seja, do que restou das habitações de negros fugidos no período escravocrata. Para o autor, tem que haver um deslocamento dessa compreensão: "não é discutir o que foi, e sim discutir o que é e como essa autonomia foi sendo construída historicamente". Tratar sobre a questão quilombola implica reconhecer não só um processo histórico, mas também a atualidade desses grupos na conformação sociocultural do país, bem como de sua importância para as dinâmicas sociais dos locais onde tais grupos se localizam.

A comunidade quilombola Poço dos Cavalos, da qual faço parte, fica situada na zona rural do município de Itacuruba, no Sertão de Pernambuco. Segundo as estimativas do Instituto Brasileiro de Geografia e Estatísticas (IBGE) para 20195 , esse município totaliza 4.918 habitantes, que em sua maioria são indígenas e quilombolas já que em Itacuruba territorializam-se três povos indígenas (Pankará no Serrote dos Campos, Tuxá Campos e Tuxá Pajeú) e três comunidades quilombolas (Negros de Gilu, Ingazeira e Poço dos Cavalos).

Segundo Silva (2019), a conformação de quilombos nesse município se dá principalmente pelo fluxo de "negros alforriados" que procuravam possibilidades de sobrevivência às margens do Rio São Francisco, onde podiam plantar e pescar. Os quilombolas de Poço dos Cavalos, para o autor, descendem de trabalhadoras e trabalhadores dos engenhos, fazendas e casas de farinha daquela região, sendo a Fazenda Fortaleza, da família dos Cantarelli, um lugar convergente para estes e estas. Nessa fazenda, trabalharam mulheres importantes para a história e memória de nossa comunidade, é o caso de Mariana Préa e Maria Preta, sendo estas as matriarcas da família de Valdeci Ana dos Santos Nascimento, fundadora de nossa Associação quilombola e importante liderança local.

Reconhecer a realidade vivida no quilombo Poço dos Cavalos para compreender a construção de uma pedagogia própria é o propósito deste trabalho. Visamos, a partir disso, ampliar as discussões sobre os processos locais de transmissão de conhecimentos e a valorização cultural e identitária quilombola. Temos como eixo de reflexão a história de vida e trajetória sociopolítica da primeira professora quilombola dessa comunidade, Valdeci Ana, conhecida como "Professora Valdeci" e "Dona Valdeci".

4 As legislações referentes aos direitos sociais quilombolas denominam estes grupos de "remanescentes", no entanto, neste trabalho optamos por utilizar o termo "quilombola" já que estes não podem ser vistos a partir de um modelo passadista, que entende unicamente os e as quilombolas como "remanescentes", como sugere Almeida (2002).

5 Disponível em: https://cidades.ibge.gov.br/brasil/pe/itacuruba/panorama. [Acesso em 17 mar. 2020].

EntreRios - Revista do PPGANT -UFPI -Teresina • Vol. 3, n. 1 (2020) 
A professora Valdeci foi capaz de afrontar um histórico de discriminações sociais e raciais e estabelecer a sua própria pedagogia, que tem a educação como uma estratégia de subversão da ordem social vigente. A valorização de quem somos, a forma como localmente ensinamos e aprendemos, e a compreensão de nossa realidade sociopolítica como ponto de partida para educar - essa é a pedagogia de Valdeci. Por outro lado, reflete a forma de ser, viver e trabalhar em comunidade, onde a coletividade é entendida como uma ação humana emancipadora.

A trajetória de luta da minha comunidade pelo reconhecimento enquanto quilombola e o papel social da mulher nessa empreitada foi um dos aspectos que me motivou a desenvolver este trabalho. Pretendo, portanto, destacar o lugar de uma importante liderança quilombola feminina, no contexto da trajetória de sua comunidade, o que provoca, ao mesmo tempo, uma reflexão sobre a sua própria história de vida e de sua importância sociopolítica para Poço dos Cavalos.

Para construção deste escrito realizei uma entrevista com Valdeci Ana. Nessa mesma oportunidade, a entrevistada me forneceu revistas com reportagens sobre a sua trajetória de vida e, ainda, sua biografia feita a próprio punho. Busquei também outras informações, depoimentos e variados registros sobre a mesma, reunidos aqui. Também me utilizei da leitura de textos que abordam sobre a história de nossa comunidade, e sobre a questão quilombola de modo mais geral. A minha condição de mulher quilombola, integrante da comunidade pesquisada, faz com que eu considere minhas próprias percepções e vivências, o que conforma uma importante dimensão metodológica na elaboração deste trabalho.

Para além do reconhecimento de uma figura feminina, entendo que o presente artigo é de grande significância para a comunidade, tendo em vista o contexto atual de lutas para garantir os nossos direitos territoriais, assim como uma escola no território, o que possibilitaria o fortalecimento de nossa cultura e de nossa identidade quilombola.

Outro elemento que ressalta a importância de registrar a história de Poço dos Cavalos é o fato de que esta comunidade historicamente é afetada pela construção de grandes megaempreendimentos energéticos. É o caso da construção da Barragem de Itaparica, responsável por inundar a antiga Itacuruba e deslocar, em 1988, as famílias de suas terras, o que provocou, em dado momento, a separação de nosso grupo e um processo extremamente traumático que deixou consequências irreparáveis. Atualmente, somos ameaçados pela construção de um novo empreendimento, agora, uma central nuclear com seis usinas nucleares.

Compreender a história de Poço dos Cavalos é um exercício de reflexão sobre a diversidade de sujeitos históricos que compõem uma comunidade que luta não somente pelo direito à terra, mas por variados direitos, sendo um deles o de ser diferente. Com o intuito de demonstrar a importância histórica e social de Poço dos Cavalos, ressaltando o papel sociopolítico de Valdeci, organizei o referido artigo em três tópicos.

No primeiro, faço uma apresentação sobre mim e o meu interesse no tema do trabalho, bem como do processo de elaboração deste, o que corresponde às questões metodológicas na construção de uma pesquisa. No segundo, dedico-me à biografia de Valdeci Ana, ressaltando o importante papel desta como liderança na comunidade de Poço dos Cavalos. No terceiro e último, descrevo a história da comunidade e as lutas pelo território e por uma escola específica. Por fim, nas considerações finais, destaco o papel social das mulheres, tendo em vista a história de Valdeci no processo de luta e organização sociopolítica do grupo. 


\section{Histórias que se intercruzam}

Proponho neste trabalho destacar as lutas e papel sociopolítico de uma professora quilombola, liderança de sua comunidade, Poço dos Cavalos, da qual também faço parte. A minha história de vida se intercruza com a história da comunidade, que, ao mesmo tempo, reflete na história de Valdeci Ana e corresponde às questões metodológicas deste trabalho já ressaltadas anteriormente.

Eu, mulher, quilombola e professora, reflito sobre a importância de outra figura feminina, que como eu, luta para a construção de uma escola em Poço dos Cavalos. A escola que queremos é pautada no direito a uma educação específica e diferenciada, que reafirme nossa história de resistência, nossa identidade étnica, nossos saberes, nosso jeito próprio de ensinar e aprender, que seja presente e participativa na cotidianidade da comunidade, reconhecendo e respeitando todos os nossos espaços, onde nossas crianças e jovens aprendam e se eduquem, assim como o fazem na roça, na pescaria, nas festas tradicionais, nas reuniões comunitárias, nos terreiros das casas.

Para construção deste trabalho, realizei uma entrevista com Valdeci Ana em agosto de 2019, enquanto cursava a Especialização em Educação Intercultural: Indígenas e Quilombolas, ofertado pelo Instituto Federal de Educação, Ciência e Tecnologia do Sertão Pernambucano Campus Floresta. O objetivo era realizar uma atividade da disciplina "Recursos didáticos e decolonialidade", que propunha explorar as possibilidades de tais recursos. Quis, já naquele momento, abordar a história de vida de Valdeci a partir de uma entrevista narrativa. Nessa mesma oportunidade, a entrevistada me forneceu revistas com reportagens sobre sua trajetória de vida e, ainda, sua biografia feita a próprio punho.

Desde então, me entusiasmei com a possibilidade de reconhecer a trajetória de vida e importância que Valdeci tem para a nossa comunidade e, mais ainda, para os que têm a oportunidade de conviver e aprender com ela. Assim, na ocasião de realizar esse feito busquei outras informações, depoimentos e variados registros sobre a mesma. Minha condição de mulher, quilombola, professora e pertencente a Poço dos Cavalos, fez com que eu considerasse minha própria história de vida, percepções e experiências na elaboração dessa discussão. Por isso, dedico este tópico à apresentação da minha própria história e percurso na comunidade, o que reflete no meu interesse e motivação pelo tema aqui abordado.

A minha história de vida tem uma relação forte com o campo desde a minha mais tenra infância. Nasci em 1983, na Fazenda Coité no município da velha Itacuruba, terras hoje inundadas pelas águas do Rio São Francisco em razão da construção da Barragem de Itaparica. Venho de uma família humilde, o meu pai agricultor e pescador e a minha mãe também agricultora, sempre trabalharam em lavouras vivendo da agricultura para garantir o sustento de nossa família.

Na infância, vivíamos nas terras que pertenciam ao meu avô paterno, descendente dos Tuxá na Bahia. Já a minha avó, era considerada cabocla ${ }^{6}$ quilombola. É desta relação que descende a nossa autoafirmação étnica. Segundo Silva (2019), a questão étnica em Itacuruba é compreendida a partir de um "complexo" de situações históricas, fluxos culturais e processo de mobilidade geográfica comuns entre os grupos quilombolas e indígenas nessa região do Sertão. Como afirmou a própria Valdeci Ana para o autor:

6 Silva (2008 apud Silva, 2019) afirma que os povos indígenas em Pernambuco durante muito tempo foram oficialmente chamados de "remanescentes" e conhecidos pelo senso comum como "caboclos". No contexto de Itacuruba o termo ainda é utilizado tanto pela sociedade envolvente quanto por alguns grupos étnicos para se referirem aos indígenas Pankará da Serra do Arapuá como aos indígenas Tuxá. Nesse caso específico, para se referir a relação entre indígenas e quilombolas. 
[na velha cidade] dançava-se o toré, mas o negro era quem dançava o toré, porque o que mais existia era o negro, e o negro dançava o toré. Por que o negro dançava? Porque a gente já tinha a origem, aquela mistura do índio com o quilombola. Meus avós, por exemplo, meus bisavôs, por exemplo, alguns eram índios, outros quilombolas (Valdeci Ana, 31/07/2018) ${ }^{7}$. [grifo meu].

Esse momento da infância foi marcado pela fartura, pois o meu avô, à época, era um dos maiores produtores de arroz. Era cultivada a maioria dos alimentos que precisávamos para viver, além da criação de animais para consumo de carnes. Meu pai também pescava e caçava para garantir o nosso alimento. Frequentávamos a cidade somente em dias de feira, quando precisávamos comprar insumos, roupas, calçados e outras coisas que não eram produzidas na roça.

Lembro-me dos banhos de rio, em tanques feitos para armazenar água, até em valetas abertas para molhar a plantação. Recordo também dos banhos de riacho quando chovia, da alegria em subir nos pés de frutas e, lá mesmo, se deliciar com as frutas frescas. Todas as noites sentávamos nos terreiros, ou deitávamos em esteiras feitas das palhas das bananeiras, para ouvir as belas histórias contadas pelos mais velhos. Brincávamos com as cantigas de rodas, adivinhações, pula corda, esconde-esconde.

No entanto, tudo isso mudou radicalmente quando em 1988 tivemos que nos mudar em razão da construção da Barragem de Itaparica, deixando assim nossas terras férteis debaixo d'água. Foram momentos difíceis, abandonar toda aquela riqueza, as belas ilhas rodeadas de uma rica fauna e flora. Foi um desastre ambiental desmedido, era o nosso território, um pedaço de nossa história que ficava para trás.

As famílias tiveram que se separar, tomando diferentes rumos em busca da sobrevivência, algumas seguiram para a nova cidade, outras para os projetos de irrigação construídos pela Companhia Hidrelétrica do São Francisco (CHESF), responsável pelo reassentamento das famílias atingidas pela Barragem. Parte de minha família se mudou para a Agrovila Coité, em uma área bem próxima da antiga Fazenda Coité, que hoje está submersa pelas águas do São Francisco. Meu pai, até os dias de hoje, reside nessa Agrovila, bem como parte das famílias da comunidade quilombola de Poço dos Cavalos.

A "nova" Itacuruba é construída, então, em um contexto de "descaso planejado", como categorizou Scott (2009), onde se proliferam diversificadas formas de violência sobre sua população:

Na cidade pernambucana de Itacuruba, inundada e reconstruída em novo local, a população residente não conta, como contava antes, com áreas de produção agrícola próximas, já que os habitantes das áreas rurais ou foram reassentados em projetos especiais distantes em torno de cem quilômetros (Projeto Brígida ou Projeto Caraíbas), ou foram reassentados dentro da própria nova cidade de Itacuruba, sem acesso a terras para plantar. A combinação de influência de políticos locais e a promessa do fornecimento de uma solução técnica para o problema de terras impróprias para agricultura, através de projetos consorciados de aves, suínos e peixes (piscigranjas) levou muitos ex-agricultores a escolher a opção de morar na cidade. $\mathrm{O}$ fracasso dos projetos consorciados e o decréscimo acentuado de atividades econômicas produtivas e comerciais após o reassentamento resultou numa superlotação da cidade em relação às suas possibilidades, contribuindo para o incremento de demandas para solucionar os problemas dos seus residentes, sobretudo dos "para-rurais" (designação técnica dos administradores dos projetos para moradores urbanos que viveriam de atividades agrícolas no campo). Como resolver estes problemas estava na pauta de estudo pelos administradores do reassentamento (SCOTT, 2009, p.139).

7 Parte do depoimento foi publicado na dissertação de mestrado do autor em 2019. Tive acesso ao conteúdo da entrevista na íntegra e utilizei neste trabalho alguns trechos não publicados, com o consentimento do autor. 
Minha família, assim como as outras reassentadas na Agrovila Coité, enfrentaram diversas dificuldades. Sem disponibilidade de terras para plantar, as pessoas tiveram que se organizar em associações para fazerem empréstimos junto ao Banco do Nordeste e, assim, desenvolverem projetos de criação de aves, suínos e peixes em piscigranjas também construídas pela CHESF que, sem sucesso, foram à falência e geraram dívidas com tal banco. Meu paipassou a trabalhar como diarista ou meeiro, quando encontrava alguém que tivesse alguma pouca terra agricultável. Meu avô paterno comprou a Fazenda Pereiro, próximo à cidade, porém distante da água, o que desfavorecia a plantação.

Apesar das dificuldades, meu pai e minha mãe fizeram questão de manter os filhos na escola, almejando uma vida melhor para nós. Dessa maneira, iniciei na Agrovila Coité o meu trajeto de estudos. Dedicada e sonhadora, aprendi a ler muito cedo, tendo como exemplo minhas tias, irmãs de meu pai, Anastácia, Dasdores e Magnólia, todas elas professoras que me ensinaram na infância.

Nessa direção, segui em busca do sonho de estudar e ser professora, assim como minhas tias. Cursei a fase primária na Escola Municipal Gerson Pires de Araújo, na zona rural de Itacuruba, e em seguida, me desloquei para a cidade, onde estudei o Ensino Fundamental na Escola Professora Maria de Menezes Guimarães. Na época, não existia mais o curso de magistério na cidade, foi quando decidi me mudar para Belém do São Francisco, município vizinho, onde terminei o ensino médio e cursei o magistério na escola Maria Emília Cantarelli no ano 2000. Concluída essa etapa fui morar em Floresta, onde casei e dessa união tive o meu primeiro filho, adiando o sonho de cursar uma graduação.

A vida me direcionou para caminhos diferentes dos quais tinha planejado, me afastei dos estudos, pois, na época, não tinha condições de custear a universidade. Em 2007, retornei para Agrovila do Coité; mesmo sem ter a graduação, consegui um contrato na Prefeitura Municipal de Itacuruba como professora do ensino primário na mesma escola em que havia estudado na infância.

Enfrentei muitos desafios na trajetória de professora. Trabalhava com uma classe multisseriada em uma escola que não tinha os recursos necessários para atender a demanda deestudantes, muitos desses oriundos das comunidades rurais vizinhas. No entanto, buscava realizar o meu trabalho da melhor forma possível, com responsabilidade, compromisso e, principalmente, dedicação e amor à profissão de educadora. Todas as dificuldades enfrentadas me fizeram crescer enquanto pessoa, enquanto mulher, enquanto professora. Porém, sentia a necessidade de melhorar o processo de ensino para uma melhor aprendizagem dos educandos, que, em sua maioria, eram os quilombolas de Poço dos Cavalos moradores das mediações da Agrovila Coité.

Cada vez mais foi sendo necessário estudar sobre minhas origens, sobre a história de meus antepassados para transmitir conhecimentos para meus alunos, que avançavam nas séries escolares, mas desconheciam as origens de nossa cultura, pois esta não era vivenciada no espaço escolar, muito menos os nossos saberes tradicionais eram considerados pelo ensino "padronizado" que prepara o aluno apenas para o mercado de trabalho. O desafio era me qualificar para contribuir com uma educação que considerasse a minha comunidade quilombola.

Nesse processo de reflexão e estudo, busquei ajuda dos mais velhos da comunidade para melhor entender a nossa história coletiva. A partir de então, estabeleci um contato maior com Valdeci Ana, liderança comunitária que, à época, já havia fundado a Associação quilombola .

8 Para a titulação e posse de um território quilombola a mesma tem que estar juridicamente organizada e representada por meio de uma associação. A Associação quilombola de Poço dos Cavalos é composta por um coordenador, um secretário, um tesoureiro e um conselho fiscal formado por seis membros - três titulares e três suplentes. No momento de realização deste trabalho, Valdeci estava como secretária da Associação. 
Valdeci foi minha guia nessa caminhada, sua orientação e ensinamentos fizeram a diferença em minha formação. Despertou-me, assim, o interesse de compartilhar tais conhecimentos, visibilizar sua importância sociopolítica para nossa comunidade e para a sociedade itacurubense em geral.

Em 2010, quando eu já integrava a Associação quilombola, soube por Valdeci que o governo federal estava oferecendo, gratuitamente, o curso de Licenciatura em Educação do Campo, específico para populações do campo ou profissionais nessa região. A mesma incentivou as pessoas da comunidade a se inscreverem, ajudando com a documentação necessária para seleção.

Nessa oportunidade pude cursar a minha licenciatura com habilitação em linguagens e códigos no Centro de Ensino Superior do Vale do São Francisco (CESVASF), em Belém do São Francisco. Durante o curso, que concluí em 2014, participei do Programa Institucional de Bolsas de Iniciação à Docência (PIBID) e de outras experiências que contribuíram para minha formação no contexto da Educação do Campo.

Lecionei durante sete anos na Escola Municipal Gerson Pires de Araújo, que não é específica para quilombolas, entretanto a maioria dos alunos são oriundos de Poço dos Cavalos. Não estou lecionando nesse momento, o que não me impede de almejar uma escola em nosso território quilombola que esteja em consonância com a nossa realidade e necessidade local.

Foi com essa perspectiva que decidi cursar a Pós-graduação em Educação Intercultural Indígenas e Quilombolas e desenvolver a presente pesquisa nesse espaço. Entendo que esta é relevante para nossa comunidade quilombola, mas também para os não quilombolas que precisam conhecer e compreender a nossa história e a nossa importância sociopolítica, sobretudo de mulheres quilombolas, que lideram suas comunidades e lutam pela propagação de nossa cultura, nossos costumes, bem como do devido respeito e reconhecimento que merecemos.

Apresentar a importância de conhecer e preservar a memória de Poço dos Cavalos, através da história de Valdeci Ana, uma mulher aguerrida e determinada a manter as tradições, é motivo de orgulho para mim, mulher quilombola. É a certeza de que também posso e quero contribuir no fortalecimento de nossa identidade eluta.

\section{Como ensina Valdeci: "nada para nós, comunidades, sem nós".}

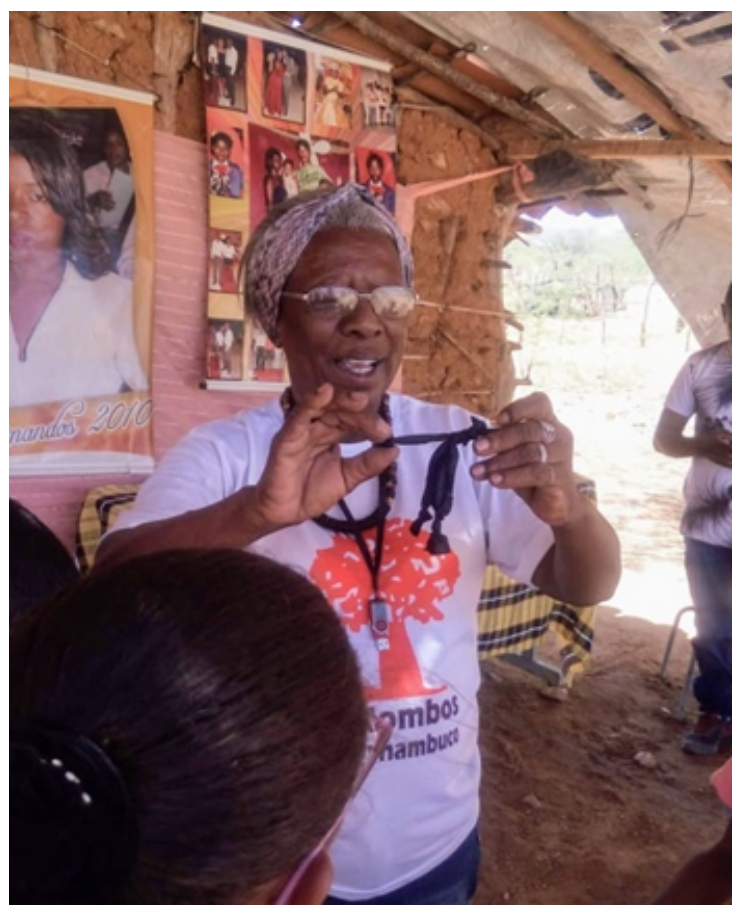

Figura 1: Valdeci ensinando as crianças da comunidade a fazerem uma boneca abayomi, no evento da consciência negra realizada em Poço dos Cavalos, em 20 nov. 2019. Fonte: a autora. 
"Nada pra nós, comunidades, sem nós" é uma frase autoexplicativa frequentemente proferida por Valdeci Ana nos eventos e seminários em que participa. A "professora Valdeci", como é chamada, nasceu e cresceu no município de Itacuruba, onde até os dias de hoje tem dedicado suas habilidades pedagógicas para educar as diferentes gerações deste local, mesmo não estando mais na sala de aula ou na gestão escolar.

Nascida em 05 de Março de 1954 na fazenda Poço dos Cavalos na velha Itacuruba, é uma mulher, quilombola e mãe, que se destaca por sua bravura, ânimo e destreza. Segunda filha de nove, que tivera José Miguel dos Santos com Ana Antônia da Conceição, lembra que aos 06 anos de idade já era autodidata. Residindo na zona rural do município, aprendeu a ler e escrever praticamente sozinha, pois não tinha o apoio e incentivo de seus pais para estudar.

Eu me auto alfabetizei, isto é, através da minha curiosidade aprendi o alfabeto e comecei a formar palavras e frases, até que minha mãe descobriu que eu estava lendo e comprou lápis, caderno e a carta do ABC. Aí eu me completei. Fiquei tão desenvolvida que quando fui fazer a matrícula não precisei cursar a $1^{\circ} \mathrm{e} \mathrm{a} 2^{\circ}$ serie primária, como era chamada na época. Foram feitos testes para eu obter as notas das duas primeiras séries e fui me matricular na $3^{\circ}$ série (Valdeci Ana, 08/2019).

Com muito ânimo em estudar, aos 09 anos já era requisitada por toda comunidade para fazer pequenas anotações. Mas, ela queria ir além. Ingressou nas Escolas Reunidas Rurais da Luz Cantarelli, ainda na velha cidade, para cursar o antigo ginásio. Com muita insistência conseguiu convencer seus pais a deixá-la morar no município de Floresta, onde residiu e concluiu o magistério em 1975, aos 21 anos. Lembra como tudo aconteceu:

Por minha avó, neto dela não estudava em casa de branco, e meus padrinhos eram brancos. Então, pedi para minha mãe me levar para tomar a benção à madrinha, que morava na cidade. Na hora de ir embora eu agarrei com ela e pedia para não deixar que me levassem, porque eu queria estudar. E lá mesmo eu fiquei, com a roupa do corpo (Valdeci Ana, 03/ 2018).

Em 1976, começou a ensinar na Escola Professora Maria de Menezes Guimarães, inicialmente como contratada pela Prefeitura Municipal de Itacuruba, mas ainda no mesmo ano foi efetivada pelo Estado de Pernambuco. Integrante da igreja católica, foi também nesse mesmo ano que começou sua missão de evangelizar nas comunidades rurais como catequista, celebrante leiga e integrante de pastorais, o que faz até os dias de hoje com muita dedicação e afeto.

Casou-se em 1977, aos 23 anos, e fruto dessa relação teve quatro filhos: Alexsandra, Alessandro, Leandro e Sandra. Em 1988, teve que se mudar para a nova Itacuruba. Um tempo difícil de adaptação por ter que deixar embaixo d'água a sua terra querida e com ela todas as suas memórias.

A velha Itacuruba era um espaço diferente e era um tempo diferente. [...] Até mesmo a base econômica da comunidade era diferente, as pessoas não eram tão necessitadas quanto hoje. A base da economia era a agricultura familiar, todos trabalhavam, até mesmo as crianças trabalhavam nas roças. Todo mundo tinha o seu troquinho no final de semana e vivia bem, tinha uma sobrevivência de uma forma saudável. [...] Hoje a gente vive aqui nessa cidade onde a agricultura é praticamente extinta; algumas pessoas que têm umas manchinhas de terra plantam alguma coisa, porém não dá pra contemplar toda a comunidade. Aqueles que realmente viviam do seu trabalho braçal, trabalhando alugado pra sobreviver, até isso aqui hoje dificultou. E também a forma da gente viver e conviver era totalmente diferente, as pessoas eram mais participativas, mais saudáveis, mais dinâmicas. Acontecia muito diálogo, hoje as pessoas são mais distantes umas das outras (Valdeci Ana, 31/07/2018). 
Lembra com saudosismo do modo de viver no velho município e da relação com o Rio São Francisco. Coloca com frequência nos espaços de discussão que: "nós tínhamos um rio de águas correntes, agora nós temos um lago de água parada" ${ }^{9}$, o que provocou diversos problemas na economia e nas dinâmicas locais.

\begin{abstract}
Na velha cidade, antes da Barragem, principalmente partindo do Poço dos Cavalos, do Coité e do Fernando, que são fazendas próximas. As famílias viviam da tecelagem, teciam suas redes, levavam para feira para vender em Itacuruba, Floresta, Belém. Faziam suas louças, seus potes de barro, suas panelas de barro, vendiam no dia da feira em Itacuruba. Faziam suas esteiras com palha de banana porque era muita bananeira e se faziam suas esteiras e vendiam. Tinha um plantio enorme de arroz, por sinal, hoje a gente não planta mais. E as pessoas viviam assim, trabalhavam assim... nas casas de farinha. A gente passava a noite e era uma alegria nas casas de farinha, raspando a mandioca pra fazer sua farinha. Hoje a gente não tem mais nada disso, acabou tudo! Existiam os engenhos, onde se fazia a rapadura, o mel. Então todo mundo trabalhava e hoje a gente não tem mais. E hoje essas coisas todas, acabou! A gente vem na luta, tentando resgatar... que eu não gosto nem de dizer assim o resgate, tentando aflorar tudo isso, e a gente enfrenta dificuldades (Valdeci Ana, 31/07/2018).
\end{abstract}

Valdeci formou-se em Geografia no Centro de Ensino Superior do Vale do São Francisco (CESVASF) em junho de 1986, antes da triste mudança para a nova cidade. Na nova Itacuruba, esteve à frente da gestão da Escola Professora Maria de Menezes Guimarães entre 1989 e 2005, onde realizou um excelente e memorável trabalho. Em 2004, começa o processo de organização e mobilização de Poço dos Cavalos enquanto comunidade quilombola, desbravando até os dias de hoje lutas pelo reconhecimento de nossos direitos sociais e a posse definitiva de nosso território. Quando perguntada sobre como se tornou liderança quilombola, responde:

Tendo em vista o caminhar do meu povo, o modo de viver e através de ter tomado reportagem vendo o andar de outras comunidades, então eu resolvi organizar meu povo e nesta organização eu fui escolhida pelo próprio povo pra ser liderança. E a gente vem andando nesse processo, tentando organizar o povo e já vem uma caminhada um pouquinho longa, mas ainda o resultado não é satisfatório, porque o povo começa a entender agora o processo do que é ser quilombola (Valdeci Ana, 31/07/2018)

9 Depoimento realizado em maio de 2015 em oficina do Projeto Nova Cartografia Social. Extraído do Boletim Informativo: "Resistimos para existir: dizemos não à usina nuclear no São Francisco". Disponível em: http:/ / novacartografiasocial.com.br/download/01-resistimos-para-existir-dizemos-nao-a-usina-nuclear-nosao-francisco/. [Acesso em 31 jan. 2020]. 


\section{Uma mulher determinada a manter as tradições}

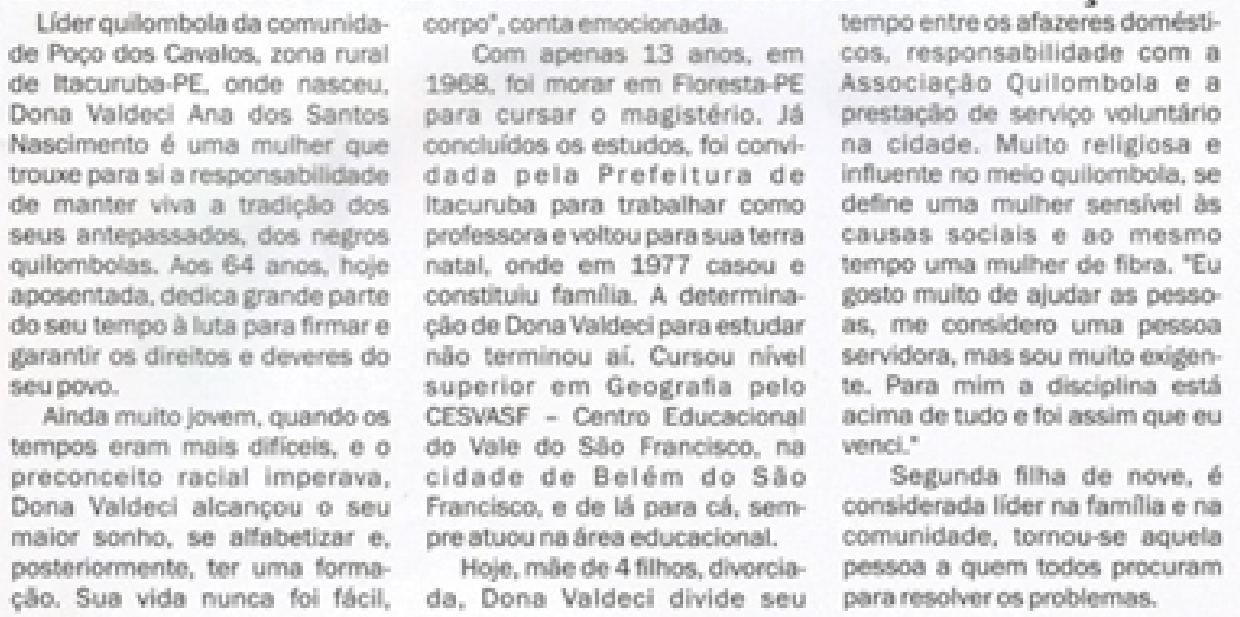

ça. Sua vida nunca foi facil. principalmente por nầ ter o apoio da familia para estudar.

"Meu deseio de estudar asorou ainda muito pequena, porém meus pais nalo estimulavam. Entâo, com apenas 6 anos eu fugia de casa para assistir aula na turma de adultos e foi assim que me alfabetizei, praticamente soxinha*, lembra.

Aos 9 anos. Dona Valdeci já era recuisitada por toda comunidade para fazer pequenas anotacóes e ela queria ir além, com muita insistência conseguiu convencer seus pais a deixb-la morar na cidade $e$, assim, dar continuidade acs seus estudos.

Ela lembra com precisło como tudo aconteceu. "Por minha avo. neto dela nầo estudava em casa de branco, e meus padrinhos eram brancos. Entla, pedi para minha mue me levar para tomar a bènçào a madrinha, que moravis na cidade. Na hora de ir embcra eu agarrei com ela e pedia para nalo deloar que me levassem. porque eu queria estudar, E la mesmo eu fíquel, com a roupa do

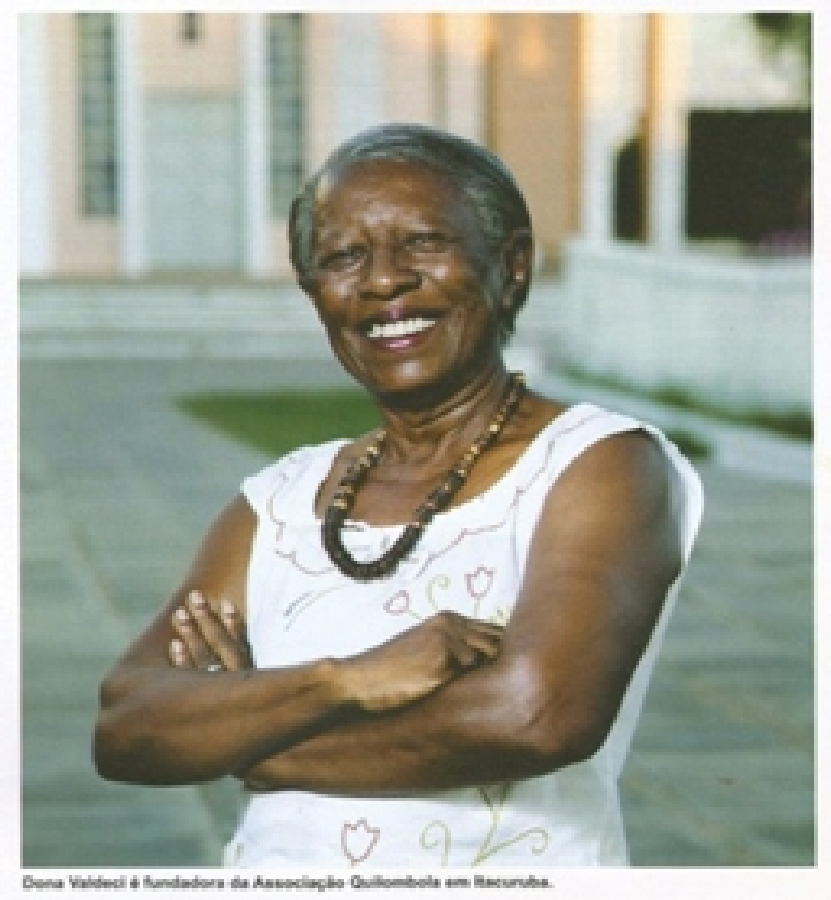

Figura 2: Reportagem sobre Valdeci Ana. Fonte: Revista Movimentto de março de 2018.

Valdeci também fez parte da Coordenação Estadual de Articulação das Comunidades quilombolas de Pernambuco ligada à Coordenação Nacional de Articulação das Comunidades Negras Rurais Quilombolas (CONAQ). Conta que o processo de reconhecimento quilombola em Pernambuco teve seus primórdios na década de 1990, e era organizado principalmente por três pessoas: Gilvânia, da Comunidade de Conceição das Crioulas em Salgueiro, Zé Carlos, da Comunidade de Castainho em Garanhuns, e Expedito, da Comunidade Timbó também em Garanhuns.

Fez-se necessário aumentar o grupo para acompanhar e fortalecer as comunidades, e então foi organizada uma comissão, que convidou lideranças quilombolas de cada região administrativa do Estado de Pernambuco, entre estas as do Sertão de Itaparica. Assim, em 2006, Valdeci começou a participar das reuniões da comissão e em evento de eleição dos membros da comissão, no município de Gravatá (PE), foi eleita membro colaborador dessa comissão. 
No âmbito da coordenação estadual, Valdeci representou, até 2019, a microrregião do Sertão de Itaparica junto com Verinha, de Tiririca dos Crioulos em Carnaubeira da Penha, que esteve como suplente. Como representante dessa região, ela procurou atender três comunidades quilombolas em Floresta (PE), uma comunidade em Petrolândia e as três comunidades de Itacuruba: Negros de Gilu, Ingazeira, além de Poço dos Cavalos.

Hoje aos 65 anos, aposentada, dedica-se ao trabalho na paróquia de Itacuruba como membro do Conselho Pastoral Paroquial e presta serviços voluntários no município. Integra também a gestão do Centro Cultural Direito de Ser em Itacuruba, bem como a gestão da Associação quilombola de Poço dos Cavalos. Na comunidade, empenha-se com vigor para atender as demandas coletivas, realizando-se ao ver as tradições dando frutos e fortalecendo as raízes.

Valdeci se define como sensível às causas sociais e, ao mesmo tempo, uma pessoa de fibra: "Eu gosto muito de ajudar as pessoas, me considero uma pessoa servidora, mas sou muito exigente! Para mim a disciplina esta acima de tudo e foi assim que eu venci" ${ }^{10}$, relata com entusiasmo. Valdeci é exemplo de coragem, força, alegria e determinação. Pessoa que inspira e motiva todas e todos ao seu redor para que nunca desistam frente aos desafios. A Professora Valdeci tornou-se inspiração de luta para Poço dos Cavalos, e, como nos ensina: "nada para nós, comunidades, sem nós!".

\section{Multiplicando as lutas da professora: Queremos reconhecimento, território e a nossa escola.}

Silva (2019) aponta dois movimentos que levaram à ocupação negra na região do Sertão do São Francisco, o que culminou na formação de quilombos em Itacuruba: a primeira a partir de um sistema escravocrata nessa região que fomentou a fuga de escravos e a conformação de quilombos próximos às áreas de resistências indígenas; o segundo movimento relacionado a escravos alforriados e às dinâmicas de mobilidade desses na região do Sertão após a "abolição da escravatura", que fez com que estes vissem a possibilidade de sobrevivência nas beiras de rios e ilhas, onde podiam plantar e pescar, sendo o Rio São Francisco um desses.

Segundo os mais velhos, a principais referências de origem da comunidade são: a Fazenda Fortaleza, onde trabalhavam na condição de alforriados, e as ilhas do São Francisco, onde plantavam e pescavam para subsistência.

\footnotetext{
As comunidades quilombolas de Poço dos Cavalos e de Ingazeira, assim como a de Negros de Gilu, lembram-se da ocupação na antiga cidade de Itacuruba atrelada ao trabalho nas propriedades da família Cantarelli, que exercera grande poder econômico e político da região por longos anos. Tanto Poço dos Cavalos quanto Ingazeira referem-se à descendência de negros alforriados que trabalhariam nos engenhos, fazendas e casas de farinha daquela região. A Fazenda Fortaleza, da família dos Cantarelli, seria um lugar convergente do "trabalho braçal" de negros que estavam no Vale do São Francisco após um extenso período de sistema escravocrata (SILVA, 2019, p.70).
}

Foi na Fazenda Fortaleza que trabalharam duas mulheres importantes para a história e a memória de Poço dos Cavalos: Mariana Preá e Maria Preta, ambas matriarcas da família de Valdeci Ana, tiveram respeitável papel nesse processo de manutenção e tradição da comunidade quilombola. Das ilhas do São Francisco, hoje inundadas, resultam a forte relação dos quilombolas com os povos indígenas da região: como os Tuxá de Rodelas, que viviam e vivem do outro lado do Rio, na Bahia; os Pankararu do Brejo dos Padres, que vinham do município de Petrolândia; e, principalmente, os Pankará, que desciam da Serra do Arapuá, município de Carnaubeira da Penha. Com estes últimos, nós mantemos relações sociais, religiosas e de parentesco até os dias de hoje (CCLF, 2008).

10 Depoimento de Valdeci Ana para Revista Movimentto, publicada em março de 2018.

EntreRios - Revista do PPGANT -UFPI -Teresina • Vol. 3, n. 1 (2020) 
O nome da comunidade, segundo os mais velhos, faz menção a um poço que nunca secava, e por isso os vaqueiros que transportavam boiadas para outros municípios tinham esse poço como um ponto de parada onde os animais bebiam água, assim, essa comunidade ficou conhecida como "Poço dos Cavalos".

\begin{abstract}
A territorialidade da comunidade de Poço dos Cavalos remete a ideia de 'pontos de passagem', seja quando se memora que o poço que daria o nome à comunidade era um lugar de parada dos viajantes que ali trilhavam com seus gados, seja quando o grupo refere-se à dimensão da relação histórica com os indígenas que ali transitavam: os Tuxá, os Pankararu de Brejo dos Padres e, sobretudo, com os Pankará da Serra do Arapuá. A relação entre Poço dos Cavalos e Pankará desembocará em complexos étnicos permeados por momentos de interação e também de conflitos. Em entrevista, a liderança da comunidade [Valdeci Ana] relata que na velha cidade os quilombolas de Poço dos Cavalos estabeleceram relações de parentesco, o 'parentesco do casal', e, também de amizade com os indígenas que moravam na Serra do Arapuá, que desciam para trabalhar nas ilhas existentes em Itacuruba antes da UHE Itaparica: 'Vinham nas festas de terreiro, de dançar toré, do dia da cura, de preparar e fazer receita, de consultar o povo através dos guias. Era Poço dos Cavalos junto com o pessoal da Serra do Arapuá', contou-me. (SILVA, 2019, p.75). [grifo meu].
\end{abstract}

A história de Poço dos Cavalos está fortemente marcada pela inundação de seu território tradicional, em razão da construção da Barragem de Itaparica que, em 1988, fez com que as famílias se separassem, já que foram reassentadas em diferentes lugares, provocando muita tristeza e danos para nós. Os dados de 2006 do Conselho Regional de Medicina de Pernambuco $(\mathrm{CREMEPE})^{11}$ demonstram essa realidade: um alto índice de suicídios e de pessoas com problemas de saúde mental, ocasionadas pela ociosidade provocada pela inexistência de empregos e de terras férteis para o trabalho na agricultura.

Mesmo que o nosso território tradicional tenha sido levado pelas águas, nossos saberes, nossa cultura e a nossa história repassada pelos mais velhos asseguram a nossa identidade quilombola e nos fortalece enquanto sujeitos políticos na luta por nossos direitos. No entanto, o nosso território está sendo ameaçado mais uma vez por um novo empreendimento do governo federal relacionado à produção de energia; silenciosamente estratégias são traçadas para aprovação e construção de uma central nuclear às margens do Rio São Francisco. Não pensam no nosso bem-estar, na luta que temos para recuperar o território. Ainda hoje, tentamos unir as famílias que foram separadas, famílias essas afetadas economicamente, socialmente e psicologicamente com a construção da Barragem de Itaparica.

Não há transparência ou participação popular no acesso as informações sobre a questão da construção da central nuclear em nosso município, mas o nosso povo, junto aos outros povos tradicionais em Itacuruba e região, vêm realizando diversas mobilizações contra a instalação desse empreendimento (SILVA, 2020).

Reconhecida e certificada pela Fundação Cultural Palmares (FCP) em outubro de 2006, a comunidade quilombola Poço dos Cavalos foi sociopoliticamente organizada em 2004 por Valdeci Ana que, escolhida pela própria comunidade, tornou-se uma das principais lideranças comunitárias, como também de nossa Associação quilombola. Segundo ela, a ideia de formar a Associação na comunidade surgiu no momento em que a mesma decidiu pesquisar sobre os seus antepassados, o que a motivou a reunir o nosso povo para dialogar sobre o movimento quilombola que, num esforço coletivo, que preparou a documentação e solicitou o registro de auto reconhecimento da comunidade.

11 Notícia intitulada: “Sertão tem grande número de suicídio", publicada em 03 de maio de 2006. Disponível em: http:// www.cremepe.org.br/2006/05/03/sertao-tem-grande-numero-de-suicidio/. [Acesso em 04 dez. 2019]. 
Hoje, existem 207 famílias cadastradas e divididas entre a zona urbana e rural da nova Itacuruba, devido aos impactos do processo de reassentamento. A falta da posse definida de nosso território é também um dos motivos da distância das famílias, sendo esta uma luta prioritária de nossa comunidade. O processo de regularização fundiária está em aberto desde 2010 no Instituto Nacional de Colonização e Reforma Agraria (INCRA), mas, até o presente, momento nada foi feito.

Os territórios tradicionais além de assegurar a sobrevivência dos povos e comunidades tradicionais, constituem a base para a produção e a reprodução de todo o seu patrimônio cultural. A realidade atual reflete a necessidade de mudanças que permitam a estes povos e comunidades a experiência de viver sua cidadania, sem que tenham que abrir mão de suas práticas culturais, sociais e econômicas. Assegurar o acesso ao território significa manter vivos na memória e nas práticas sociais os sistemas de classificação e de manejo dos recursos, os sistemas produtivos, os modos tradicionais de distribuição e consumo da produção, além de elementos simbólicos essenciais à sua identidade cultural (BRASIL, 1988, apud MONTE ALTO, 2012, p.52).

Assim como as demais comunidades quilombolas existentes no município de Itacuruba, Poço dos Cavalos tem enfrentado graves problemas de invasão de suas terras por pessoas da região não pertencentes ao grupo, além das consequências de vendas, desapropriações e indenizações, em razão da Barragem de Itaparica, o que vai desfavoravelmente reconfigurando a ocupação territorial da comunidade. Atualmente, nos territorializamos em quatro localidades que conformam o nosso território: Coité, Riacho do Caroá, Lagoa Cercada e Poço dos Cavalos. Apenas 52 famílias moram nessas localidades, as demais residem na cidade.

A religião predominante na comunidade é a católica. A religiosidade é um dos elementos que visibilizam as estratégias de resistência quilombola ao longo do tempo, é nesse contexto que se misturam nossa cultura e a religiosidade católica. Um momento emocionante para o grupo, por exemplo, foi retomar os festejos de nossa Senhora da Saúde, padroeira da comunidade, que acontece no período de 24 de Janeiro a 02 de Fevereiro.

Nossos antepassados participavam desses festejos tradicionais. Estamos trabalhando para também voltar a praticar o São Gonçalo, dança que os mais velhos realizavam para pagar suas promessas; os rituais sagrados como a via sacra, que é realizada no período da quaresma; a dança da palma, que é uma dança de roda onde as pessoas cantam e vão criando versos sobre a vivência na comunidade; e as mais variadas brincadeiras antigas, que hoje as crianças envolvidas por esse mundo tecnológico não conhecem mais. Valdeci diz ter ficado emocionada quando realizou a primeira festinha de Dia das Mães, como também a primeira celebração eucarística. As mães, também emocionadas diziam: "a gente nunca teve isso aqui" - contou a liderança quilombola.

Atualmente, Poço dos Cavalos vive em situação de carência socioeconômica e tem problemas relacionados à insegurança alimentar, à mobilidade, ao aceso à saúde, moradia, entre outras políticas públicas. Entretanto, continuamos na resistência de lutar e buscar nossos direitos sociais, específicos e diferenciados.

Hoje, o grupo é coordenado por Evanildo José da Silva que, junto à nossa comunidade, trava uma luta constante para assegurar os nossos direitos. Apesar de ter fundado a Associação, Valdeci decidiu se ausentar das atividades na comunidade por três anos. Após esse período, o grupo procurou novamente por Valdeci, pois sentiram dificuldades em seguir em frente com as atividades sem os seus conhecimentos e orientação. Hoje, além de ser uma importante liderança do grupo, também ocupa a função de secretaria da Associação. 
Valdeci relata que muitas mulheres de nossa comunidade ainda levam uma vida política ociosa, no sentido de dedicarem-se apenas às atividades domésticas, muitas vivem apenas do Bolsa Família que recebem do governo, outras são diaristas quando aparece algum trabalho voltado para agricultura nas redondezas. "Essas mulheres ainda se sentem inseguras e um pouco acomodadas... elas ainda acham que eu, Valdeci, é que tenho que tomar as decisões. Estou trabalhando para quebrar este tabu", afirma ela.

Apesar das dificuldades na organização social do nosso povo, e sabendo que muitas outras mulheres poderiam exercer um papel fundamental junto às lideranças na propagação dos saberes tradicionais e de nossa cultura, mas se ausentam dessa missão, estamos conseguindo retomar e reelaborar algumas das tradições, costumes e valores repassados pelos antepassados. Entretanto, a construção de uma escola em nosso território, pautada nas especificidades de nossa comunidade, nos fortaleceria na educação das crianças e jovens.

Esse é um dos desafios que a comunidade enfrenta atualmente, visto que para ter acesso à educação escolar, os estudantes de nossa comunidade têm que se deslocar para cidade e estudar em escolas que não compreendem nossa realidade local. Não nos interessa aqui criticar a educação oriunda de escolas urbanas, mas assegurar que o campo, em sua diversidade, seja reconhecido como espaço possível e real da democratização do saber sistematizado:

A Educação do Campo não se concretiza sem reconhecer a existência do campo, de sua realidade histórica e dos sujeitos que nele vivem, compreendendo seus processos culturais, sua socialização e as relações de trabalho vivenciadas por esses sujeitos do campo em suas práticas cotidianas (MONTE ALTO, 2012, p.34).

Ter um espaço pedagógico como a escola dentro da própria comunidade é de fundamental importância para sistematização e compartilhamento dos saberes. Atualmente, esse processo se dá através de moradores mais velhos elideranças do movimento, em espaços de debate, embaixo de árvores, nos terreiros das casas. Ainda em passos lentos, geralmente em dias e datas comemorativas, como o Dia da Consciência Negra, Dia das Crianças, Novenário da padroeira da comunidade, que é celebrado nas casas das pessoas por falta de uma capela.

Mesmo frente a diversificadas dificuldades, a professora Valdeci Ana não se omite da tarefa de transmitir e compartilhar os saberes em Poço dos Cavalos, pelo contrário, está constantemente em busca de melhorias para sua comunidade. A mesma realiza diferentes atividades, como confecção de objetos como bonecos, colares, pulseiras, entre outros enfeites decorativos usando materiais da terra (sementes, cabaças, galhos, entre outros) e materiais recicláveis, sempre compartilhando e expondo nos eventos das datas comemorativas.

Valdeci Ana é uma das responsáveis por mobilizar as estratégias de organização sociopolítica, como as reuniões comunitárias, a distribuição de tarefas, o fortalecimento da parceria com outros professores engajados no movimento. É surpreendente sua inteligência e capacidade pedagógica, com apenas alguns registros fotográficos e muitas histórias na arguição. Valdeci vem superando os desafios surgidos no dia a dia de nossa comunidade, buscando sempre novas perspectivas de vida. É dessa forma que ela, mulher, quilombola e professora, junto ao nosso povo guerreiro está numa luta incansável em busca de engajar cada sujeito social no movimento de buscar seus direitos, sobretudo por respeito a nossa diversidade e realidade local. 


\section{Considerações finais}

O exercício construído através deste trabalho se revelou para mim como uma maneira de aprender e refletir mais sobre a história e trajetória sociopolítica da minha comunidade, Poço dos Cavalos. Foi também importante ressaltar a relevância de uma mulher, professora quilombola, que tem partilhado sua vida para luta e defesa dos direitos quilombolas. Ao mesmo tempo, fazer isso foi uma experiência também de reconhecimento de meu papel sociopolítico enquanto mulher, quilombola e também professora.

As mulheres quilombolas, assim como Valdeci, exercem um importante papel no processo de construção da identidade coletiva, é através delas que têm sido transmitidos nossos valores, nossos ensinamentos, nossa cultura e nossas tradições. A presença feminina nos espaços de poder dos grupos sociais em nosso município é algo comum, mesmo que ainda equivocadamente no imaginário social sejamos consideradas um "sexo frágil" para o enfrentamento de determinadas situações.

Por outro lado, este trabalho apresentou que o processo de construção da identidade quilombola está relacionado à nossa história e memória, bem como nossa trajetória de lutas por direitos, e essa é uma construção que se dá de forma gradual, histórica e circunstancial. Dessa maneira é muito importante que nós, quilombolas, saibamos de onde viemos, pois somente através da consciência crítica, do conhecimento e da autonomia local superaremos os obstáculos provenientes da discriminação social e do racismo.

A nossa organização social parte do princípio da luta pela terra, levando em conta nossos saberes próprios, os ensinamentos dos mais velhos. O direito à terra é essencial para nós e se constitui numa demanda principal, já que é o maior desafio a ser garantido. A terra implica não só o território, mas a memória dos antepassados, a preservação da cultura e os modos de vida, enfim, o direito de existir e ser reconhecido como sujeito de direito e sujeito político.

As mulheres estão unidas nessa luta, além de trabalhar nas lavouras, nos afazeres domésticos, ou em variadas outras profissões, seja também no cuidado com os filhos, têm participado de maneira significativa nos movimentos quilombolas, mostrando a potencialidade e versatilidade feminina nas reivindicações dos direitos sociopolíticos de suas comunidades. No entanto, ainda sofrem com o machismo e a falta de representatividade política.

Em Poço dos Cavalos, percebemos um avanço nessas discussões. As mulheres, como Valdeci Ana, têm contribuído num processo bem sucedido de preservação e reelaboração cultural das tradições, da cultura, das festividades. Os mais velhos se emocionam, os adultos participam, os jovens começam a despertar, as crianças começam a identificar o seu espaço, é o surgimento de um novo tempo.

A nossa comunidade, assim como outros movimentos sociais, busca a autonomia local e luta por seus próprios espaços de interação no campo. É preciso reconhecer a diversidade de espaços educativos - a casa, a rua, debaixo do pé de árvore, a dança, o terreiro, o ritual, a luta pela terra, as reuniões da Associação e as assembleias - mas não abrir mão do direito à uma educação escolar quilombola específica, diferenciada e intercultural, que ensine o respeito à diversidade e que esteja voltada para o desenvolvimento sustentável de nossa comunidade. Queremos uma escola em nosso território para mostrar para os nossos jovens a educação e sabedoria de seus territórios tradicionais, garantindo a continuidade da nossa existência e de nossas lutas.

Por fim, é sempre importante ressaltar que as mulheres da comunidade quilombola Poço dos Cavalos, mesmo que ainda de forma tímida e a passos lentos, como disse a própria Valdeci, estão despertando para o repensar de seus papéis sociopolíticos no sentido de assegurar nossos direitos e sobrevivência. Valdeci Ana e várias outras mulheres têm sido as diretamente envolvidas na organização do movimento quilombola não só em Poço dos Cavalos, mas também no Sertão de Pernambuco, lutando por direitos e justiça social. 
42 I A pedagogia de Valdeci

\section{Referências}

ALMEIDA, Alfredo Wagner Berno de. "Os quilombos e as novas etnias". In: O'DWYER, Eliane Cantarino (org.). Quilombos: identidade étnica e territorialidade. Rio de Janeiro: Editora FGV, 2002.

BRASIL. Constituição da República Federativa do Brasil. Brasília, DF: Senado Federal: Centro Gráfico, 1988.

Decreto $n^{o}$ 4887, de 20 de novembro de 2003. Brasília, 2003. Disponível em: <http://www.planalto.gov.br/ccivil_03/decreto/2003/D4887.htm>. [Acesso em: 31 jan. 2020].

CENTRO DE CULTURA LUIZ FREIRE. Sertão quilombola: a formação dos quilombos no sertão de Pernambuco. Olinda: CCLF, 2008.

MONTE ALTO, Rosana Lacerda. Saberes e fazeres quilombolas: diálogos com a educação do campo. Dissertação de mestrado. PPGE, Universidade de Uberaba, 2012.

SCOTT, Russel Parry. Negociações e resistências persistentes: agricultores e a barragem de Itaparica num contexto de descaso planejado. Recife: Ed. Universitária da UFPE, 2009.

SILVA, Whodson. "Sumir do mapa e outros scripts: táticas de resistir à instalação da central nuclear em Itacuruba". Revista Continente. ed. 231, março de 2020.

O conto das quatro mil almas: uma etnografia do confronto de Indígenas e Quilombolas com a Central Nuclear do Nordeste em Itacuruba. Dissertação de mestrado. PPGA, Universidade Federal de Pernambuco, 2019.

. Entrevista com Valdeci Ana dos Santos em 31 de julho de 2018 na sua residência no município de Itacuruba. Material de pesquisa do autor (Circulação restrita).

VALDECI, Ana dos Santos: uma mulher determinada a manter as tradições. Movimento a revista que valoriza Pernambuco. Recife, n. 93, p.41-41, mar. 2018. 